\title{
Addiction to Modern Gadgets and Technologies Across Generations
}

Dr. Ranjan Bhattacharyya

MD, DNB (Psychiatry), PhD trainee, Asst Professor \& HOD,

Deptt of Psychiatry, Murshidabad Medical College \& Hospital,

West Bengal, India.

\section{ABSTRACT}

The modern gadgets and technology have become predominant determinants of socioeconomic status and not only is restricted to teenagers but is spreading fast across generations. Addiction to technology is causing significant loss of productivity as well as problems in interpersonal relationships. It has been postulated that rather than a separate entity, internet addiction is a manifestation of a variety of depression, anxiety, impulse control disorders or pathological gambling. There have been rehabilitative measures to correct internet overuse. Technophobia is the fear or dislike of modern technology particularly computers. Let us welcome the technological revolutions with a widespread awareness of its potential danger. The generation of today needs to move ahead with bright vision and better tomorrow.

\section{INTRODUCTION}

"The day will come when technology will surpass human interaction."

\section{- Albert Einstein}

The list of modern day gadgets is exhaustive and includes Laptops, iPads, iPods, Video games, Smart phones and playstations. These modern gadgets and technology have become predominant determinants of socioeconomic status and is not only vastly popular amongst teenagers and young adults but are fast spreading across all generations. This

\section{Corresponding Author :}

Dr Ranjan Bhattacharyya

Mob : 9433053389

Email : drrbcal@gmail.com

Website : www.drranjanbhattacharyya.com increasing dependence on technological gizmos has far-reaching consequences.

Parents often complain that their sons or daughters are increasingly addicted to their mobile phones or play video games and watch television the whole day. Human intelligence has evolved, so have our gadgets and the internet. Mechanised communications in social networking sites have largely replaced warm interpersonal interactions that once formed the basis of lasting bonds and relationships. 'Emotions' have been replaced by Emoticons'. It would not be wrong to say that "Man has become slaves to the modern day gadgets." In the words of the Michael Condry the chief operating and development officer of Sledgehammer Games, "All these gadgets, the phone and the computer, they expose the inside of your brain in a way that's bad." People prefer to spend their weekends and spare time at home in front of these gadgets. 
Children spend hours on end in front of laptops playing video games and social networking. Even pornography, erotica, dating websites and sex games are just a small'click' away. The parents are not fully aware of the provisions of family filter, internet site selection, and channel selection in televisions. As a result children are often exposed to the harmful effects of these materials. Children are becoming lazy, inactive and more aggressive. They are addicted to video games which often contain materials of extreme violent nature. Tender childly emotions have been replaced by rudeness adamance and defiance. The nuclear family structure and busy modern day schedule of working parents have made the opportunity of priceless human interactions bleaker. In today's world, people prefer to socialize on the internet more and more rather than face-toface. There are frequent showdowns between the parents and children. Children no longer respect their parents and more than often parents view children as their competitors. Albert Einstein once expressed his concern that technology will surpass human interaction. That day has arrived.

Judicious use of internet is always advisable. Google can act as a gold mine of information for all kinds of people, young and old. The patterns of internet addiction across various generations are different. Selfies or "photographing of the self" and posting the pictures in the internet are the new trends in the social media. The internet is flooded with pictures of models, actors and actresses who upload their personal photographs for public view. The practice is no more confined to the celebrities. The generation $\mathrm{Y}$ has adopted this trend in no time. A recent study has explored the relationship between selfie-posting, photo-editing and personality disorders. ${ }^{1}$

It explored the inter-relationship between selfobjectification and the three traits (known as the Dark triad of narcissism, psychopathy and machiavellianism). The study concluded that posting of higher number of selfies in the social media were directly related to narcissism and psychopathy.
Addiction to technology is causing significant loss of productivity as well as problems in interpersonal relationships. The internet has paved the way for the waves of globalisation to spread its claws into the smallest households of the country. It is high time now to formulate a comprehensive approach to curb the unrestricted use of the internet. Recently an incident where a teenager committed suicide on losing his mobile phone has shaken the nation to its root. Such slavery for gadgets are indeed worrisome.

We often witness people crossing busy roads and busy intersections and railway tracks listening to ipods or talking over the phone. This has lead to increase in the number of accidents.

Over-use of mobile phones can affect social and psychological well-being and health. The article was about a teenager boy from china who sold his "kidney" just to buy an iPhone for himself. Corresponding incidences and trends in developing nations like India are also on the rise. ${ }^{2}$ Enormous amount of research has been directed in the last decade on mobile phone use and its influence on the human mind and body. It has been concluded that excessive mobile phone users may encounter increased stress, disturbances in sleep and symptoms of clinical depression. These symptoms are especially prominent in young adults. ${ }^{3}$ Internet addiction disorder (IAD) or more commonly called problematic Internet use (PIU) or compulsive Internet use (CIU) or even iDisorder are now the common disorders of generation $Y ., 5,6$ The nomenclature was originally proposed in a satirical hoax by Ivan Goldberg, M.D., in 1995. However, some time later, it started to be used as a more generalised term denoting excessive uncontrolled use of the internet. He used the model of pathological gambling (diagnosed by the Diagnostic and Statistical Manual of Mental Disorders (DSM-IV) as his model for the description of IAD. Lack of standardization in identifying PIU seems to be the major barrier in classifying this as a psychiatric disorder. ${ }^{7}$ 
IAD can be categorised into subtypes by the type of activity, like gaming; online social networking; blogging; email; viewing Internet pornography in excess; or even Internet shopping (shopping addiction). However, all compulsive behaviors may not be necessarily addictive. ${ }^{8}$ A recent study suggests that the prevalence of Internet addiction varies considerably among different countries and is inversely related to the quality of life. ${ }^{9}$ Addiction researchers, psychologists, healthcare providers as well as older adolescents have contributed data to build a conceptual model of PIU. ${ }^{10,11}$

That study put forward seven concepts, or clusters suchas:psychosocialriskfactors; physical,emotional, as well as social and functional impairments; risky Internet use; impulsive Internet use; and Internet use dependence. ${ }^{12}$ Risky Internet use are those behaviors that increase the risk of harmful consequences. Harmful effects include difficulty in memory and concentration, emotional turbulence, anxiety, insomnia, compulsive disorders as well as depression. The impulsive use is the inability to control internet use in day-to-day life. Finally, dependent use describes extreme situations like withdrawal symptoms. ${ }^{10}$ Internet addiction disorder is not yet listed in the latest DSM manual (DSM-5, 2013), which is commonly used by psychiatrists all over the world. ${ }^{13}$ The only behavioural (nonsubstance related) addiction included in DSM-5 is gambling disorder. However excessive Internet gaming is listed in an appendix as a disorder requiring further study. ${ }^{14}$

Jerald J. Block, a leading psychiatrist observed that diagnosis of Internet addiction was difficult since $86 \%$ of study subjects presented with symptoms pertaining to various other mental health disorders. ${ }^{15}$ Young explained "Internet addiction" as a broad term that include addiction to 'cyber sex', 'cyber relationships', 'net compulsions', 'information and research' and 'computer gaming'. 'Internet Addiction' is actually addiction to the 'content' available online like gaming, shopping, gambling cyber-relations and anonymity, hence internet serves as the tool necessary to fuel these addictions. ${ }^{16}$ Thus, excessive Internet users are actually not Internet addicts per say. Another study by Young elaborated that the new users of the internet were the ones who were addicted more than regular users who have been using the internet over a period of a year and were largely nondependant, conforming to the concept that internet addiction may wane over time. ${ }^{17}$ Young the founding member of The Centre for On-Line Addiction claims Internet addiction covers five principal subtypes of behavioural and impulse control disorders that include:

1. Cybersexual addiction: addiction to cybersex and cyberporn.

2. Cyber-relationship addiction

3. Obsessive online gambling, shopping or day-trading.

4. Compulsive and over-excessive web surfing or database searches.

5. Obsessive computer gaming. ${ }^{18}$

Hypersexuality and Internet pornography use has come under the scanner in recent years. ${ }^{19,20}$ Internet pornography is very common in the West. ${ }^{21}$ There has been a dramatic rise in mental disorders as an aftermath of pervasive internet pornography addiction..$^{22,23}$

Joshua B. Grubbs, a specialist in Addictive Behavior Patterns, that at present there is no single prevalent consensus regarding Internet pornography addiction and hence the defining Internet pornography use as an addiction is very much controversial. ${ }^{24}$ The current Diagnostic and Statistical Manual of Mental Disorders (DSM-5) does not classify Internet pornography as an addiction. However, hypersexuality is mentioned while discussing other disorders. ${ }^{25}$ But there is no independant entity as hypersexual disorder in DSM-5. While pornography is mentioned in DSM-5, pornography is not identified as a mental health problem. Cyber-Relationship addiction has been defined as an impulse-control problem within Internet Addiction Disorder; it has 
been described as an addiction to social networking in all forms. ${ }^{26,27}$

Cyber-Relationships are in essence a virtual relationship or form of communication between two people. Anonymity and privacy in relationships are something that are cherished by many. Over time virtual online friends win importance over time to real-life family and friends. People who experience social phobia and anxiety issues can find a suitable vent for their emotional necessities. However, these virtual relationships have more than often devastated real lives. Criminal intentions are always in search of weak unsuspecting minds. The fake profiles and its dire consequences had been cinematized in the movie named "catfish" after the famous documentary film was released in 2010. These fake profiles are often created in the social networking sites with vile intentions and people are often tricked into false relationships. Robbery, thefts, kidnappings, blackmailings and even murders have been the aftermath of such intentions. Many people have suffered irretrievable personal losses due to internet social networking addiction.

The term addiction or habituation has largely been replaced by the term "dependence" Mobile phone addiction has been added in the long list of psychoactive substance abuse, alcohol and tobacco under ICD 10. ${ }^{28,29}$ Shambare et al. claim that cellphone use is "possibly the biggest non-drug addiction of the 21st century;" ${ }^{\prime 30}$ The results of two studies aimed to explore the behavioral aspects associated with the use of excessive use of mobile phones clearly showed that college students, as well as nonstudents, reported problematic mobile phone use and their behavior fulfilled a number of the addiction criteria. Mobile phone use has been attributed to increasing number of accidents and accidental deaths. Mishaps occur due to negligence not only on the part of the driver but also on the part of the pedestrian. In majority of accidents, talking over phone while crossing roads or driving cars are responsible for these mishaps. Mobiles have replaced the warm personal interaction that once formed the basis of a healthy familial relationship. However it has also fostered increased connectivity across huge distances. High speed internet has enabled excellent resolution in video calling, multimedia messaging (also popular as "MMS"). These have truly made any place in the universe "accessible" and "within the reach" which previously was unimaginable. Thus Internet has its fair share of goodness as well. ${ }^{31}$

Two scales, a 20-item self-reported Problematic Use of Mobile Phones (PUMP) scale, and Mobile Phone Problem Use Scale (MPPUS), estimated the prevalence of avid internet users among British adolescent population and found it to be approximately $10 \%$ among those aged $11-14$ years and corresponding figures in India were estimated to be $39-44 \% .{ }^{28,32,33,34}$ In contrast, the prevalence of Internet addiction was $4.9-10.7 \%$ in Korea and is a serious public health concern. ${ }^{34}$

Addictive behaviour is more common among women as compared to men..$^{35}$ Women tend to use mobiles more for social purposes than men do. Older people tend to use mobiles the least for social purposes. This is the largely due to lesser popularity and greater self-regulation among elders. ${ }^{36}$ In another survey by Gazelle, $44 \%$ participants reported anxiety and irritability on being unable to interact with their phones for a week. ${ }^{37}$

Approximately, $70 \%$ people use their mobile phones within the first hour of getting up in the morning. $56 \%$ of the subjects check their phones before going to bed. $51 \%$ check their phones constantly even during holidays. A study in Egypt showed that the risk of transmitting micro-organisms by medical staff via mobile phones is much higher. ${ }^{38}$

Although substantial evidence is still lacking, there has been speculation that overuse of mobile phones can lead to cancer, specially brain cancer. In 2011, the International Agency for Research on Cancer of the World Health Organisation suggested that radiofrequency can be a probable human carcinogen. Links were established between use of mobile phones and the potential risk of developing glioma. ${ }^{39}$ 
Headaches, impaired memory and concentration, fatigue, dizziness and sleep disturbance has been associated with radiation sickness. ${ }^{40,41}$ A study links insomnia to the use of cell phone before bed. In 2014, 58\% WHO states issued guidelines to the general population to cut down radiofrequency exposure below heating guidelines. The major recommendation was to use hands-free kits and to reduce call time duration, apart from using text messaging and avoiding calls with low signals or using phones with low SAR. ${ }^{42}$ In 2015, Taiwan banned toddlers from using mobile phones and France withdrew wifi from toddlers' nurseries. ${ }^{43,44}$

The genera of mobile phone that are used for multitasking could be called as "Smartphone" and had the features of PDA( Personal digital assistant). In todays world, smartphones have touchscreen userinterface, camera, media player, radio, innumerable apps, motion sensors and even independant GPS navagation unit. Nowadays smartphones have been operating high speed mobile broadband 4G LTE internet and mobile bill payment solutions.

Nomophobia or "no-mobile-phobia" is a new term that has gained popularity. The psychological factors like low self-esteem and lack of self confidence are the basis of this behaviour. It is likely that these individuals suffer from social phobia, social anxiety disorder and/or panic disorder and this kind of behaviour is an external manifestation of underlying phenomena based on the study that investigated the anxieties suffered by 2163 mobile phone users in Britain. $^{45,46}$

Kathy Scherer, a psychologist from the The University of Texas at Austin asserted that, ${ }^{\prime \prime} 13 \%$ of college internet users fit the criteria for Internet addicts". In her study, Scherer enrolled 531 college students. Further it was revealed that " $72 \%$ of the Internet addicted students were men". ${ }^{47}$

Cyber dependency was found on an average in 5\% and $10 \%$ of Web surfers in a study and depression and anxiety were common among internet addicts. ${ }^{48}$
Compulsive Internet use has been linked to morphological changes in the brain. A study among Chinese college cyber addicts found reductions in the sizes of the dorsolateral prefrontal cortex,rostral anterior cingulate cortex, supplementary motor area and parts of the cerebellum Although these changes can signify learning type cognitive adaptations for efficient cyber use, there was impairment of shortterm memory and decision-making skills. ${ }^{49}$ Changes in the brain ultra-structure were also found in internet addicts as revealed by a 2009 study and these neurobiological correlates are similar to chemical addiction as evidenced by MRI studies which revealed that internet addicts had impaired grey and white matter integrity in the orbitofrontal cortex of the prefrontal regions of the brain. ${ }^{50,51}$

The orbitofrontal cortex is important to execute functions like planning and prioritization, remembering details as well as controlling our motivation". ${ }^{52,53}$ It has been postulated that rather than a separate entity, internet addiction is a manifestation of a variety of depression, anxiety, impulse control disorders or pathological gambling. Parallels have been drawn between internetaddiction and food disorders where overeating acts as a relief from depression and anxiety; or impulse control disorders where the person is addicted to bidding, pornography, gaming and gambling, whether or not they are online or offline. ${ }^{54,55}$

Byun et al. asserted the fallacies of most of the studies as they have inconsistent criteria for defining net addicts resulting in conspicuous sampling bias and investigates degree of association rather than causal relationships. ${ }^{56}$ Pathological use of the internet can lead to increase in job losses, divorce rates, financial debts and academic failures according to a Korean study. $70 \%$ of internet users play online games, and $18 \%$ among them are addicts of online gaming. The gamers documented that addiction to online games helped them to avoid stress in real life. Kimberley Youngs questionnaire was used in this study. ${ }^{57,58}$ 
Young discusses the findings of Dr. Maressa Hecht-Orzack of McLean Hospital whose set up for computer and internet de-addiction, received patients with depression and bipolar depression in its full depressive swing. Also patients were largely referred from different clinics throughout the hospital rather than direct self-referrals. ${ }^{59}$ The instrument used to assess cyber abuse was the Internet Addiction test by Kimberly Young classified addictive behaviour into mild, moderate and severe impairment. Available in three different languages, English, Italy and French, this was the first global psychometric measure. ${ }^{60}$

The Compulsive Internet Use scale (CIUS) developed in 2009 consists of 14 items and rated on a 5-point scale from $0=$ never and $4=$ very often.Some other scales are Problematic and Risky Internet Use Scale (PRIUSS). The Chen Internet Addiction Scale(CIAS) is a 4-point Likert scale with 26 items, with a higher total score indicating greater severity of net addiction and is applicable to both adults and adolescents. ${ }_{61,62,63}$ In a Hong Kong based study, 18\% Chinese adolescents were reported to be net addicts. ${ }^{64}$ Some proponents commented that those who are lonely and depressed develop a preference for online interaction rather than face-to-face rendezvous. This can lead substantial negative outcomes like mood swings and withdrawal symptoms when they were away from the internet.The intrinsic deficit is not healed, but in turn its severity gets exacerbated. ${ }^{65}$

Mark D. Griffith proposed six criteria for Internet addiction and are as follows :66

1. Salience : Internet use pre-occupies individuals personal life and thought process.

2. Mood modification : The positive experience is a consequence of engaging to the cyberworld and helps in avoiding situations in life that are difficult to deal with.

3. Tolerance : Increasing the use of the internet helps to achieve a desired level of mood elevation.
4. Withdrawal symptoms : Substantial unpleasant use on discontinuation or reduction of internet use and consist of physical symptoms like tremors, mood disorders or irritability.

5. Conflict : Interpersonal conflict,conflicts with other essential activities like job, social life or even within the individual may result from net addiction.

6. Relapse : Recurrence of behavioral patterns previously observed after periods of abstinence or control.

Some researchers found on longitudinal follow up that internet addiction corrects itself over time. Some of the correction measures include softwares to restrict the content, cognitive and behavioural therapy.Rather than total abstinence, control over the internet usage is preferable. ${ }^{67}$

There have been rehabilitative measures to correct internet overuse. One of such endeavour is ReSTART, a center for residential therapy based on Seattle, Washington, USA for net addicts that offers a 45-day program to wean people from pathological internet use. ${ }^{68}$

A somewhat harsher measure was invented in August 2013 by researchers at the MIT Media Lab, USA who developed a USB connected keyboard accessory that "punishes" net addicts with a small electrical jolt every time there is excess time spent on a particular website.

Pathological gambling, according to David Hodkins, professor of psychology at the University of Calgary , is a separate entity altogether. The surge of globalisation has created a desperation for 'fast' money, particularly among young teenagers. The option of online gambling is attractive due to lack of any social inhibition and the widespread use of the internet where the gambling sites are just one click away.

Online stock trading, according to Brian Bloch is very addictive due to the sense of empowerment it 
generates as traders have the ownership over when and how stocks are traded and money distributed. The environment is free from arrogant bosses or hectic schedules that the individual encounters in a day-to-day life. They are enthralled into a cycle of imperishable desire to win money that often leads to repeated losses and bankruptcy. Video game addiction has drawn significant attention since the past decade..$^{70}$

With the advancement of technology, it has gained phenomenal proportions. Online video games flood the cyberspace. Cyber game addicts range from children to adults. Andrew Doan, with a background in neuroscience research had to fight with his mammoth internet addiction whereby he spent approximate 20,000 hours of game play spread over a period of nine years.

OnlineGamersAnonymous, anon-profitorganisation was developed in 2002 for de-addiction support for avid gamers include an array of discussion forums, online chat sessions, skype communications to help recover from the deleterious effects of internet games. $^{71}$

Jim Rossignol, a finance journalist who, similar to Andrew Doan, was a game addict himself, is now a well known reporter of internet gaming and gaming culture. ${ }^{72}$

Social network addiction is a behavioural problem that necessitates a constant urge to communicate with other people on the social media even though there is no immediate necessity for such interaction. Facebook has created a wave of communication addiction. It has become a platform for social communication, fostering relationships as well as a source of unbound entertainment. People update their status on their facebook page, sometimes even minute details of day to day life are updated. Some people are in the habit of uploading their own selfclicked pictures in the urge of getting noticed by their peers. Sharing personal moments are very much in vogue. Friends in social networking sites are seldom friends in real life. Having large numbers of friends and followers in social networking sites are regarded as indices of high social quotient. This has lead to this "virtual world addiction". Presently this addiction is limited to interactive visual media for example social media like facebook. But scientists predict the future of virtual reality to be a computer stimulated pseudo-environment that can have extreme potential for addiction. ${ }^{73}$

There is one TV addict in every household.Around $70 \%$ of Americans are TV addicts.This is still on the rise, thanks to the modern television technological advancement. LED, Plasma TVs with mammoth screens and concept of home theatres have created a revolution in the television world. People are more and more drawn inside the comforts of their homes, keeping the time for healthy social interactions completely at bay. Addictions have lead to the loss of valuable work hours in total laziness and lethargy. However TV addiction is not classified as a separate condition in DSM-IV.Technostress is the negative impact of the modern technology and includes altered work habits that is brought about by the use of these technologies at office and home situations. ${ }^{74,75}$

There exists a range of symptoms that people experience from technostress. Some of these are headache, mental exhaustion, panic, helplessness, insomnia, loss of temper, irritability, anger and frustration. Hours infront of the computer can lead to physical symptoms like backache, stiffness in the neck, shoulder and reduced job satisfaction and productivity. Jobs that have increased likelihood of developing technostress should employ adequate preventive measures like periodic assessments to check the effects of technostress on the physical and emotional aspect of the employee. There should be workshops organised for employees not only to impart knowledge and enhance their technical skills but also to make them aware of the deleterious effects of technostress. IT troubleshooters should help maximise the system accessibility and strive to make the employees more comfortable with the system. 
The principal causes of technostress are

- fast pace of technological change with lesser time for acclimatisation

- lack of adequate training

- Phenomenal workload

- Absence of standardization within technologies

- Reliability of hardware and software

Technophobia (from Greek technē, "art, skill, craft" and phobos, "fear") is the fear or dislike of modern technology particularly computers.According to Dr. Larry Rosen, research psychologist and professor at the California State University describes that there are three types of technophobes- the "uncomfortable users", the "cognitive computerphobes", and "anxious computerphobes". ${ }^{76}$

World War II and the bombings of Hiroshima and Nagasaki worked as catalysts to the existing fear and phobia.War technologies such as napalm, explosives, and gases during the Vietnam War further escalated the situation. ${ }^{77}$ The British Luddites protested the application of the machines and argued that the skills of human labour needed protection from destructionby the autonomy of machines. ${ }^{78}$

New technologies often encounter conflict with established beliefs. They contradict personal values of simplicity and modest lifestyle. Technophobic ideas can be found in various forms of art, from creative literature such as Frankenstein to science fiction drama like Metropolis. These works mainly portray the evil side of technology as perceived by the technophobic. With the technologies becoming increasingly complicated, people are more and more likely to harbor anxieties relating to the use of these advanced technologies.With the advent of modern medicine and the likes of Louis Pasteur, Charles Darwin, Gregor Mendel, Michael Faraday, Henri Becquerel, and Marie Curie, and inventors such as Nikola Tesla, Thomas Edison and Alexander Graham Bell, world was changing rapidly. Poets like William Wordsworth and William Blake harboured the thoughts that the technology was polluting the perfect and pure nature in more than singular ways.
Let us welcome the technological revolutions with a widespread awareness of its potential danger to get addicted by limited fruitful use of modern day gadgets the generation of today needs to move ahead with bright vision and better tomorrow.

Digital amnesia symptoms is the habit of automatically going online to get answers to questions. The trend to look up information before even try to recall it prevents the build up of long term memories. The loss of data stored in smart phones causes immense distress, particularly among women and people under 35. Selfitis is an obsessive compulsive desire to take selfie and post them on social media to make up for the lack of self-esteem and to fill a gap in intimacy. Acute selfitis is defined as taking photos of one's self at least three times a day and posting each of the photos to social media. Chronic selfitis is the uncontrollable urge to take photos of one's surroundings round the clock and posting the photos more than six times a day. Selfie obsession is attributed to low self-esteem as people try to find a way to boost themselves. It could be attributed to gain attention from the society. In India $74 \%$ of adolescents are found moderately addicted to their smartphones. Smartphone dependence may cause stress, depression, anxiety, insomnia, delinquency and aggressiveness (Int J of Preventive Medicine). According to researchers, the presence of ADHD increases the risk of Internet addiction. Research suggests that adolescents with IAD have more aggressive dispositions than others. Early psychiatric intervention may prevent IAD. According to recent studies on school going adolescents, boys are more likely to have internet dependency. Secondary school students, who suffer from IAD, may have psychological behavioural problems like restlessness, palpitation, tremors etc. Recent studies provide evidence of compromised prefrontal cognitive control over emotional interference in adolescents. Increased internet use predicted higher levels of social support, reduced loneliness \& psychological wellbeing among older adults. A survey of facebook overusers demonstrated novel self-other discrepant 
perceptions concerning risk and benefit of facebook. According to recent studies, late adolescents who are victims of cyber bullying, are at higher risk of depression of problematic alcohol use. IA prevalence is inversely associated with quality of life reflected by subjective (life satisfaction) and objective (environmental) indicators. According to studies, avoidant coping and coping inflexibility are the cause of psychological maladjustments in Internet Addicts. Texting while driving has become a cultural artefact, which conflicts with driver safety as well as laws prohibiting texting while driving. Recent studies suggest that online gaming is negatively correlated with college engagement and academic performance of college going students. Recent studies suggest that the extent of social anxiety is a predictor of preference for online social interaction \& IAD Cybersexual addiction is defined as a type of IAD where the addict spends excessive time on websites for cybersex or cyberporn. Data suggests that approximately $20 \%$ internet addicts are engaged in some form of online sexual activities. Problematic and repetitive sexual behaviour serves as a means to escape stress and tension, becoming a way to handle the problems. Cyberchondria is defined as anxiety induced by health related excessive online search causing hypochondriasis. Cyberchondria is caused by excessive information; patient tries to convince himself that he is suffering from illnesses, causing anxiety and depression. Individual searching for reassurance online may experience anxiety as a result of escalating search behaviour.

\section{REFERENCES}

1 Fox, J., \& Rooney, M. C. (2015). The Dark Triad and trait self-objectification as predictors of men's use and self-presentation behaviors on social networking sites. Personality \& Individual Differences. Computers in Human Behavior 2015; 45, 168-176. doi: 10.1016/j.chb.2014.11.083; 76, 161-165.

2. Davey S, Davey A. "Assessment of Smartphone Addiction in Indian Adolescents: A Mixed Method Study by Systematicreview and Meta-analysis Approach". Int J Prev Med 2014; 5 (12) : 1500-11.

3. Sara T, Härenstam A, Mats H. "Mobile phone use and stress sleep disturbances, and symptoms of depression among young adults - a prospective cohort study". BMC Public Health 2011. $11: 66$.

4. Moreno MA, Jelenchick LA, Christakis DA. "Problematic internet use among older adolescents : A conceptual framework". Computers and Human Behavior 2015; 29 : 1879-87.

5. Meerkerk GJ, Van den Eijnden RJJM,Vermulst AA, Garettsen HFL, "The Compulsive Internet Use Scale (CIUS)". Cyber Psychology \& Behavior. 2009; 12 : 1-6.

6. Rosen LD, Cheever NA, Carrier Ll. (2012). iDisorder: Understanding Our Obsession with Technology and Overcoming Its Hold On Us. New York : Palgrave Macmillan.

7. Moreno MA, Jelenchick L, Cox E, Young H, Christakis DA. "Problematic internet use among US youth : A systematic review". Archives of Pediatrics and Adolescent Medicine2011; 165 : 797-805.

8. Pawlikowsk Mi, Nader IW, Burge Cr, Stieger S, Brand M. Pathological Internet use - It is a multidimensional and not a unidimensional construct. Addiction Research \& Theory $2014 ; 22,166-75$.

9. Cecilia C, Li Angel Y."Internet Addiction Prevalence and Quality of (Real) Life : A Meta-Analysis of 31 Nations Across Seven World Regions". Cyberpsychology, Behavior, and Social Networking 2014; 17 : 755-60.

10. Moreno MA, Jelenchick LA, Christakis DA. "Problematic internet use among older adolescents : A conceptual framework". Computers and Human Behavior 2013; 29 : 1879-87.

11. Kim S. J., Byrne S. "Conceptualizing personal web usage in work contexts : A preliminary framework". Computers in Human Behavior 2011; 27 : 2271-83.

12. Trochim W., Kane M. “Concept mapping : an introduction to structured conceptualization in health care. International". Journal for Quality in Health Care 2005; 17 : 187-91.

13. American Psychiatric Association (2013). "Diagnostic and Statistical Manual of Mental Disorders". American Psychiatric Association, Washington, DC, USA. 5th edition.

14. Young, K. (2009). Issues for Internet Addiction as a New Diagnosis in the DSM-V. Washington, District of Columbia, US: American Psychological Association. Retrieved from PsycEXTRA database.

15. Block JJ. "Issues for DSM-V: Internet addiction". American Journal of Psychiatry 2008; $165:$ 306-07.

16. Griffiths M. "Internet addiction-time to be taken seriously?". Addiction Research \& Theory 2000; 8 : 413-18.

17. Young, K. Understanding online gaming addiction and treatment issues for adolescents. The American Journal of Family Therapy 2009; 37 : 355--56. 


\section{Addiction to Modern Gadgets and Technologies Across Generations}

18. Young, K. The research and controversy surrounding internet addiction. Cyber Psychology and Behavior 1999; 2, 381-83.

19. Kafka MP. "Hypersexual disorder : A proposed diagnosis for DSM-V" Archives of Sexual Behavior 2010; 39, 377-400.

20. Kalichman, S, Rompa, D. Sexual sensation seeking and sexual compulsivity scales : Reliability, validity, and predicting HIV risk behavior". Journal of Personality Assessment 1995; 65 : 586-601.

21. Carroll J., Padilla-Walker L., Nelson L,Olson C,Barry C.,Madsen S. "Generation XXX". Journal of Adolescent Research 2008; $23:$ 6-30.

22. Manning J "The impact of Internet pornography on marriage and the family : A review of the research". Sexual Addiction \& Compulsivity 2006; 13 : 131-65.

23. Owens E, Behun R, Manning J, Reid R. "The impact of Internet pornography on adolescents : A review of the research". Sexual Addiction \& Compulsivity 2012; 19 : 99-122.

24. Joshua B, Julie J, Exline K. Pargament J, Robert D. Transgression as Addiction : Religiosity and Moral Disapproval as Predictors of Perceived Addiction to Pornography. Archives of Sexual Behavior 2015; 44 : 125-36.

25. Suler J. 2004. The psychology of text relationships. Online counseling : A handbook for mental health professionals, pp. 19--50.

26. Young K. "The relationship between depression and internet addiction". Cyber Psychology \& Behavior 1998; 11 : 25-28.

27. Whang S, Lee L, Chang S. "Internet over-users' psychological profiles: A behavior sampling analysis on internet addiction". CyberPsychology\& Behavior 2003; 6 : 143-52.

28. Davey S, Davey A. "Assessment of Smartphone Addiction in Indian Adolescents : A Mixed Method Study by Systematicreview and Meta-analysis Approach".J Prev Med. 2014; $5: 1500-11$.

29. Weinstein A, Lejoyeux M. Internet addiction or excessive Internet use. The American Journal of Drug and Alcohol Abuse. 2010; 36 :: 277-83.

30. Shambare R., Rugimbana R., Zhowa T. Are mobile phones the 21St century addiction? African Journal of Business Management. 2012; 62 : 573-77.

31. Smetaniuk P. A preliminary investigation into the prevalence and prediction of problematic cell phone use. Journal of Behavioral Addictions. 2014; 3 :: 41-53.

32. Merlo LJ, Stone AM, Bibbey A. "Measuring Problematic Mobile Phone Use : Development and Preliminary Psychometric Properties of the PUMP Scale". J Addict 2013. doi:10.1155/2013/912807. PMID 24826371.
33. Lopez-Fernandez O, Honrubia-Serrano L, Freixa-Blanxart M, Gibson W. ."Prevalence of problematic mobile phone use in British adolescents". Cyberpsychol Behav Soc Netw 2014; 17 : 91-98.

34. Koo HJ, Kwon JH . "Risk and protective factors of internet addiction: a meta-analysis of empirical studies in Korea". Yonsei Med J 2014. 55: 1691-1711.

35. Roberts JA, Yaya LH, Manolis C. "The invisible addiction: cell-phone activities and addiction among male and female college students". J Behav Addict. 2014; 3 254-65.

36. van Deursen AJAM, Bolle CL, Hegner SM, Kommers PAM. "Modeling habitual and addictive smartphone behaviour : The role of smartphone usage types, emotional intelligence, social stress, self-regulation, age, and gender". Computers in Human Behavior 2015. 45 : 411-20.

37. Perlow, Leslie A. (2012). Sleeping with your smartphone : how to break the $24 / 7$ habit and change the way you work. Boston, Mass. : Harvard Business Review Press. ISBN 9781422144046.

38. "Mobile phones and nosocomial infections". International Journal of Infection Control. 2012. Retrieved 2015-04-21.

39. World Health Organization: International Agency for Research on Cancer (2011). "IARC Classifies radiofrequency electromagnetic fields as possibly carcinogenic to humans" (PDF). Press Release no. 208.

40. Al-Khlaiwi T, Meo SA. "Association of mobile phone radiation with fatigue, headache, dizziness, tension and sleep disturbance in Saudi population". Saudi Med J. 2004; $25: 732-36$.

41. Khan MM (2008)."Adverse effects of excessive mobile phone use". Int J Occup Med Environ Health. 2008; 21 : 289-93. doi : 10.2478/v10001-008-0028-6. PMID 19228576.

42. Dhungel A, Zmirou-Navier D, van Deventer E (2015). "Risk management policies and practices regarding radio frequency electromagnetic fields: results from a WHO survey". Radiat Prot Dosimetry 2015; 164 : 22-27.

43. Sarah Malm (2015). "Does YOUR toddler play on an iPad? Taiwan makes it ILLEGAL for parents to let children under two use electronic gadgets... and under-18s must limit use to 'reasonable' lengths". Daily Mail (January 28, 2015).

44. Powerwatch (2015). "Wifi banned from nurseries in France" (05/02/2015)

45. Bianchi A,Phillips J. Psychological predictors of problem mobile phone use. Cyber Psychology \& behaviour 2005; 8 : 39-51.

46. Merlo LJ, Stone AM, Bibbey A. "Measuring Problematic Mobile Phone Use : Development and Preliminary Psychometric Properties of the PUMP Scale". J Addict 2013. J Addict. 2013; 2013 : 912807. doi : 10.1155/2013/912807. Epub 2013 Sep 4. 


\section{Addiction to Modern Gadgets and Technologies Across Generations}

47. Scherer, Kathy (1997). "College Life On-Line : Healthy and Unhealthy Internet Use.". Journal of College Student Development, v38 n6 p 655-65 Nov-Dec 1997

48. Cromie, William J (21 January 1999). “Computer Addiction Is Coming On-line". Harvard University Gazette. Retrieved 8 March 2008.

49. Yuan K, Qin W, Wang G, Zeng F, Zhao L, Yang X, et al. (2011) Microstructure Abnormalities in Adolescents with Internet Addiction Disorder. PLoS ONE 6(6) : e20708. doi:10.1371/ journal.pone.002070

50. Ko C, Liu G, Hsiao S, Yen J, Yang M, et al. Brain activities associated with gaming urge of online gaming addiction. Journal of psychiatric research. 2009; $43: 739-747$

51. Jun L, Xue-ping G, Osunde I, Xin L, Shun-ke Z, et al. Increased regional homogeneity in internet addiction disorder : a resting state functional magnetic resonance imaging study. Chinese medical journal. 2010; 123 : 1904-08.

52. Cao F, Su L, Liu T, Gao X. The relationship between impulsivity and Internet addiction in a sample of Chinese adolescents. European Psychiatry. 2007; 22 : 466-71.

53. Ko C, Hsiao S, Liu G, Yen J, Yang M, et al. The characteristics of decision making, potential to take risks, and personality of college students with Internet addiction. Psychiatry research. 2010; 175 : 121-25.

54. Petersen KU, Weymann N, Schelb Y, Thiel R, Thomasius R. Pathological Internet use - epidemiology, diagnostics, co-occurring disorders and treatment. Fortschritte Der Neurologie Psychiatrie. [Review] 2009; 77 : 263-71

55. Cash H, Rae CD, Steel AH, Winkler A. Internet Addiction : A Brief Summary of Research and Practice. Current Psychiatry Reviews. 2012; 8 : 292-98.

56. Byun, $\mathrm{S}$ et al. "Internet Addiction : Metasynthesis of 19962006 quantitative research". Cyberpsychology \& Behavior $2009 ; 12$ : 203-7

57. Kim J-U. A reality therapy group counseling program as an Internet addiction recovery method for college students in Korea. International Journal of Reality Therapy. 2007; 26 : 3-9.

58. Kim J-U. The effect of a R/T group counseling program on the Internet addiction level and self-esteem of Internet addiction university students. International Journal of Reality Therapy. 2008; $27: 4-12$.

59. Young KS. "Treatment Outcomes with Internet Addicts". Cyber Psychology \& Behavior 2007; 10 : 671-79.

60. Young KS. Cognitive behavior therapy with Internet addicts : treatment outcomes and implications. Cyber Psychology \& Behavior. 2007; 10(5 ) : 671-9.

61. Chen S.H. et al."Development of Chinese Internet Addiction Scale and its psychometric study".Chin J Psychol 2003;45: 279-294.

62. Mak K.K. et al. "Psychometric properties of the Revised Chen Internet Addiction Scale (CIAS-R) in Chinese adolescents". J Abnorm Child Psychol 2014; 42 : 1237-45.
63. Jelenchick LA, Eickhoff J, Christakis DA, et al. The Problematic and Risky Internet Use Screening Scale (PRIUSS) for Adolescents and Young Adults : Scale Development and Refinement. Computers in human behavior. 2014; 35 : 10.1016

64. Shek DTL, Tang VMY, Lo CY. Evaluation of an Internet addiction treatment program for Chinese adolescents in Hong Kong. Adolescence. 2009; 4 : 359-73.

65. Amichai-Hamburger Y, Ben-Artzi E. Loneliness and Internet use. Computers in Human Behavior. 2003; 19 : 71-80.

66. Griffiths M. "Internet addiction-time to be taken seriously?". Addiction Research \& Theory 2000; 8 : 413-18.

67. Du Y-s, Jiang W, Vance A. Longer term effect of randomized, controlled group cognitive behavioural therapy for Internet addiction in adolescent students in Shanghai. Australian and New Zealand Journal of Psychiatry. 2010; 44 : 129-34.

68. reSTART : Internet Addiction Recovery Program. First detox center for Internet addicts opens its doors : Creates solutions for computer related addictive behaviors. 2009. [[cited 2011 August 21]]. Available from: http: //www. netaddictionrecovery.com .

69. Slice of MIT. "MIT Researchers Develop a Shocking Treatment for Facebook Addiction" Retrieved 2013-09-05.

70. Ko C-H, Liu G-C, Hsiao S, Yen J-Y, Yang M-J, Lin W-C, et al. Brain activities associated with gaming urge of online gaming addiction. Journal of Psychiatric Research. 2009; 43 : 739-47.

71. "CyberSightings". Cyber Psychology\& Behavior 6 (1) : 107-113. 2003. doi : 10.1089/109493103321168018.

72. Rossignol, Jim (2009). The Gaming Life : Travels in Three Cities. University of Michigan Press, ISBN 9780472033973.

73. Echeburua E., de Corral P. "Addiction to new technologies and to online social networking in young people : A new challenge". Adicciones 2010; 22 : 91-95.

74. Guzzo T, Ferri F, Grifoni P. "Social Network's Effects on Italian Teenager's Life". Journal of Next Generation Information Technology (JNIT) 2013; 4 : 54-62.

75. Ennis L. "The Evolution of Technostress." Computers in Libraries, Sept. 2005, 10-12.

76. Gilbert, David, Liz Lee-Kelley, and Maya Barton. "Technophobia, gender influences and consumer decisionmaking for technology-related products." European Journal of Innovation Management 6.4 (2003) : pp. 253-263. Print.

77. Goodyear, Anne Collins. "From Technophilia to Technophobia : The Impact of the Vietnam". Leonardo 2008; $41: 169-73$.

78. Randall, Adrien (1997). "Reinterpreting 'Luddism': Resistance to New Technology in the British Industrial Revolution" Resistance to New Technology: Nuclear Power, Information Technology and Biotechnology. Cambridge University Press. pp. 57-80. 